\title{
Acute Kidney Injury in the Critically Ill: Herein Lies the Problem!
}

\author{
Atul P Kulkarni ${ }^{1}$, Ashit Hegde ${ }^{2}$, Nagarajan Ramakrishnan ${ }^{3}$ \\ Indian Journal of Critical Care Medicine (2020): 10.5005/jp-journals-10071-23413
}

Information is the resolution of uncertainty. -Claude Shannon ("the Father of Information Theory")

The ancients knew about the bean-shaped organs that lay in the abdomen but were not sure what their function was. The ancient Egyptians believed that the kidneys were advisors to the heart, which assisted the dead in the afterlife (Book of the Dead, 1550-50 BC). ${ }^{1}$ There was a treatment for fluid retention (dropsy) in ancient Egyptian texts. Sushruta (600 BC) described in great detail the surgical removal of vesical stones. ${ }^{2}$ There is no description of renal failure in any of the ancient texts. Our knowledge of uremia is relatively new, it was described for the first time in 1850 s. $^{3}$

Acute renal failure (ARF) is fairly common in the community and its incidence is rising. ${ }^{4,5}$ The presence of ARF results in poorer outcomes in hospitalized patients. Acute renal failure is now replaced with the term acute kidney injury (AKI), and it is now described using the kidney disease improving global outcomes (KDIGO) classification. ${ }^{6}$

Acute kidney injury in the critically ill patients is common in Indian intensive care units (ICUs) and leads to adverse outcomes in as many $38-90 \%$. This issue deals with many areas related to AKI in ICU. Contrast-induced nephropathy, sometimes a gift of VOMITs (Victim Of Medical Imaging Technologies) to the patients, is a common problem. We are still uncertain about the preventive measures for this common problem. In preventive strategies for postoperative AKI, we may have some answers but not for the most important question: what should be the mean arterial pressure of the patients intraoperatively?

In the area of diagnosis of $\mathrm{AKI}$, particularly in relation to biomarkers, we are far away from finding an ideal biomarker. We know what an ideal biomarker should do, but the search for it remains elusive. Even if we do find an ideal one, it is necessary to define when and how do we use that biomarker.

Apart from this, the issue has common topics of interests to the students and practitioners: dosing renal replacement therapy in AKI, anticoagulation in RRT, and drug dosing for patients with AKI and those on RRT. In this field, many areas still lack information, and the quest for resolving the uncertainties continues.
${ }^{1}$ Division of Critical Care Medicine, Department of Anaesthesiology, Critical Care and Pain, Tata Memorial Hospital, Homi Bhabha National Institute, Mumbai, Maharashtra, India

${ }^{2}$ P.D. Hinduja Hospital, Mumbai, Maharashtra, India

${ }^{3}$ Department of Critical Care, Apollo Hospitals, Chennai, Tamil Nadu, India

Corresponding Author: Atul P Kulkarni, Division of Critical Care Medicine, Department of Anaesthesiology, Critical Care and Pain, Tata Memorial Hospital, Homi Bhabha National Institute, Mumbai, Maharashtra, India, Phone: +91-9869077526, e-mail: kaivalyaak@ yahoo.co.in

How to cite this article: Kulkarni AP, Hegde A, Ramakrishnan N. Acute Kidney Injury in the Critically III: Herein Lies the Problem! Indian J Crit Care Med 2020;24(Suppl 3):S83.

Source of support: Nil

Conflict of interest: None

\section{REFERENCES}

1. Greydanus DE, Kadochi M. Reflections on the medical history of the kidney: from Alcmaeon of croton to Richard Bright - standing on the shoulders of giants. J Integr Nephrol Androl 2016;3(4):101-108. DOI: 10.4103/2394-2916.193496.

2. Raffensperger JG, Raveenthiran V. Pediatric vesicolithotomy from ancient India to Greece, Arabia and the western world. Pediatr Surg Int 2019;35(6):737-741. DOI: 10.1007/s00383-019-04477-2.

3. Richet G. Early history of uremia. Kidney Int 1988;33(5):1013-1015. DOI: 10.1038/ki.1988.102.

4. Hsu CY, McCulloch CE, Fan D, Ordonez JD, Chertow GM, Go AS. Community-based incidence of acute renal failure. Kidney Int 2007;72(2):208-212. DOI: 10.1038/sj.ki.5002297.

5. Stucker F, Ponte B, De la Fuente V, Alves C, Rutschmann O, Carballo $\mathrm{S}$, et al. Risk factors for community-acquired acute kidney injury in patients with and without chronic kidney injury and impact of its initial management on prognosis: a prospective observational study. BMC Nephrol 2017;18(1):380. DOI: 10.1186/s12882-017-0792-2.

6. Acute Kidney Injury Work Group. Kidney disease: improving global outcomes (KDIGO) - clinical practice guideline for acute kidney injury. Kidney Inter 2012;2(1):1-138. DOI: 10.1038/kisup.2012.1.

(-) The Author(s). 2020 Open Access This article is distributed under the terms of the Creative Commons Attribution 4.0 International License (https://creativecommons. org/licenses/by-nc/4.0/), which permits unrestricted use, distribution, and non-commercial reproduction in any medium, provided you give appropriate credit to the original author(s) and the source, provide a link to the Creative Commons license, and indicate if changes were made. The Creative Commons Public Domain Dedication waiver (http://creativecommons.org/publicdomain/zero/1.0/) applies to the data made available in this article, unless otherwise stated. 